\title{
KEMASLAHATAN DALAM FIQH ISLAM (JAWABAN ATAS PANDEMI COVID-19)
}

\author{
Ahmad Subekti \\ Fakultas Agama Islam Universitas Islam Malang \\ e-mail: ahmad.subekti@unisma.ac.id
}

\begin{abstract}
Abstrak
Fiqh (Hukum Islam) dan perubahan sosial adalah bagaikan dua sisi dari sekeping mata uang. Satu dengan Iainnya senantiasa terkait dalam perjalanan waktu dan tempat. Maka ketika Fiqh yang merupakan sebuah produk pemahaman atau pemikiran atas suatu teks (AI-Qur'an dan AI-Hadits bersinggungan dengan perubahan sosial tentunya harus sanggup melakukan dialog dengan setiap wacana yang berkembang termasuk menghadapi kejadian yang luar biasa seperti adanya pandemi Covid-19 ini, sehingga pencapaian substansi yang ada di balik pemahaman itu yang tidak Iain adalah kemaslahatan akan senantiasa dapat dicapai. Sebagaimana dikatakan dalam kaidah Fiqh: "dar'ul mafasidi muqaddamun 'ala jalbi almashalihi" (menolak kemafsadatan, lebih didahulukan dari pada menarik kemaslahatan). Oleh karena itu tindakan preventif dalam menghadapi pandemi Covid-19 harus lebih diutamakan.
\end{abstract}

Kata Kunci: Kemaslahatan, Fiqh Islam, Covid-19

\begin{abstract}
Fiqh (Islamic law) and social change are like two sides of a coin. One with the other is always related in the course of time and place. So when Fiqh which is a product of understanding or thinking of a text (AI-Qur'an and AI-Hadith intersects with social change, of course, must be able to have a dialogue with every discourse that develops, including facing extraordinary events such as the Covid-19 pandemic. , so that the achievement of the substance that is behind the understanding that is not other is the benefit will always be achieved. As said in the rules of Fiqh: "dar'ul mafasidi muqaddamun 'ala jalbi almashalihi" (rejecting misinterpretation, takes precedence over attracting benefit). therefore preventive measures in dealing with the Covid-19 pandemic must be prioritized.
\end{abstract}

Keywords: Benefit, Islamic Fiqh, Covid-19

This work is licensed under Creative Commons Attribution Non Commercial 4.0 International License Available online on: http://riset.unisma.ac.id/index.php/fai/index 
Kemaslahatan dalam Fiqh Islam (Jawaban atas pandemi Covid-19)

\section{A. Pendahuluan}

Fiqh Islam adalah tidak lebih merupakan formulasi dari pemahaman terhadap syari'at yang kemudian dimaksudkan agar setiap individu Muslim dapat membangun perilaku dan pribadinya berdasarkan akidah, syariah, akhlaq Islam secara integral dan terpadu dalam bingkai substansial hukum Islam yang holistik dan komperehensif. Kalaupun dilakukan pendekatan formalistik terhadap fiqh maka sudah semestinya harus dibarengi dengan upaya mengedepankan akhlak (etika moral).

Sehingga dalam aplikasi cenderung tidak disalahgunakan atau tercerabut dari tujuan semula ditetapkannya syari'at Islam. Dari sini dapat dipahami, bahwa fiqh atau katakanlah bila ditarik dalam tataran yang lebih makro hukum Islam (HI), di satu sisi, tidak terkesan menampilkan wajahnya yang "angker" atau "kaku" (statis) dan "emah" (immon terhadap segala bentuk perubahan sosial itu tetap tampil elegan danakomodatit.

Bentuk pemahaman yang seperti diatas sebenarnya bertitik dari pernyataanAI-Qur'an sendiri (Q.S.AI-Anbiya'[21]:107,Saba'[34]:28) yang menyatakan, "dan tiadalah kami mengutus kamu, melainkan untuk menjadi rahmat bagi alam semesta, umat manusia seluruhnya sebagai pembawa berita gembira sekaligus sebagai pemberi peringatan, tetapi kebanyakan manusia tiada mengetahui". Dan semua ini diberikan oleh Allah SWT tanpa mengenal batas ruang dan waktu. Dalam hal ini, Abu Zahrah (t.t. : 277) menyebutkan, di dalam fiqh dijumpai bahwa menjaga dan memelihara kemaslahatan jiwa, akal, keturunan, dan harta itu merupakan tujuan pokok dari syara'. Statemen ini serupa dengan pendapat Ibn Jawziyah (1973 : 3) yang menyatakan bahwa kemaslahatan seperti di atas merupakan cikal bakal dari pembentukan fiqh (hukum Islam) tersebut.

Pandemi Covid-19 adalah salah satu masalah yang berkaitan dengan kemaslahatan dan pemeliharaan jiwa. Oleh karena itu ketika kita dihadapkan pada masalah ini, maka akan muncul beberapa persoalan, seperti: mana yang lebih didahulukan (maslahat) antara beribadah di rumah dan di masjid, bekerja di rumah atau di luar rumah, dan lain-lain. Dari sini, maka yang harus menjadi skala prioritas menurut teori kemaslahatan dalam fiqh adalah yang kemaslahatannya lebih luas dan urgen (penting/utama) yaitu menjaga dan memelihara jiwa, baik kemaslahatan/kesehatan jasmani maupun rohani.

JAS: Volume 2 Nomor 1, 2020 


\section{B. Metode}

Dalam penulisan artikel ilmiah ini, penulis menggunakan metode kualitatif. Metode ini Bersifat lebih ke arah metode kajian atas gagasan konseptual. Sedangkan data yang dikumpulkan dan yang akan dianalisis bertumpu pada ketersediaan sumber data di perpustakaan (Library Research).Teknik analisis data yang digunakan dalam kajian ini adalah teknik analisis isi (Content Analysis), yaitu sebuah teknik analisis yang secara komprehensif berusaha menggali beragam keterangan dari pesan atau informasi yang disajikan dalam wujud lambang atau simbol tertentu yang terdokumentasikan. Sedang gambar data penelitian ini diperoleh dari beragam sumber yang bersifat kekinian dengan tidak meninggalkan referensi klasik.

\section{Hasil dan Pembahasan}

\section{Titik Tolak dan Ruang Lingkup Fiqh Islam dan Kemaslahatan}

Seperti telah dimaklumi, bahwa fiqh itu adalah khitthab (hukum Allah) yang berkaitan dengan perbuatan mukallaf (orang dewasa), baik yang bersifat tuntutan (hukum Taklifi), yaitu tuntutan untuk melakukan suatu perbuatan (perintah) seperti hukum wajib dan sunat, maupun tuntunan untuk meninggalkan suatu perbuatan (Larangan) seperti hukum haram dan makruh. Disamping itu di dalam fiqh juga ada hukum yang bersifat pilihan (hukum Takhyiri) yaitu ketentuan hukum terhadap suatu perbuatan yang boleh dikerjakan atau ditinggalkan (mubah), serta hukum wadl'i, yaitu hukum Allah yang berkaitan dengan syarat dan sebab, seperti ketentuan wajib puasa Ramadhan setelah melihat hilal (bulan sabit) ketika matahari terbenam.

Fiqh dalam kajian Al-Qur'an dan Al-Hadits jika dilihat dari dalalah atau sumber datangnya, semua ayat Al-Qur'an bersifat qath'i (pasti) yang dinukil dari Rasul kepada kita. Ayat-ayat yang terdapat dalam Al-Qur'an jika dilihat dari dalalah hukum yang dikandungnya terbagi menjadi dua, yaitu ayat yang dikelompokkan kepada qath'iyyat al-dalalah, yaitu ayat yang dipahami akan menunjukkan makna tertentu (tidak bermakna ganda) dan tidak dapat dita'wil. Dan ayat al-Qur'an yang dikelompokkan kepada dhann-al-dalalah, yaitu ayat yang menunjukkan makna yang mungkin untuk di-ta'wil sehingga berubah menjadi makna yang lain. (Ibrahim Hosen, 1993 :59).

Khitthab (hukum Allah) itu dalam kajian hukum Islam bisa mengandung makna syariah atau fiqh. Syariah adalah hukum Allah yang sifatnya Qath'i, yaitu aturan hukum yang kebenarannya bersifat absolut 
Kemaslahatan dalam Fiqh Islam (Jawaban atas pandemi Covid-19)

(pasti/baku/tidak bisa diubah-ubah lagi). Sedangkan fiqh adalah aturan hukum yang kebenarannya bersifat dhanni (bisa berubah/berbeda) karena ada unsur ijtihad manusia di dalamnya. Karenanya, fiqh menerima perubahan dan perbedaan pendapat antara yang satu dengan yang lainnya.

Dari uraian di atas bisa disimpulkan, bahwa Syariah adalah hukum Allah yang sudah pasti dan tidak bisa diubah-ubah lagi, seperti contoh kewajiban shalat lima waktu, puasa ramadhan, menunaikan zakat, haji, menegakkan keadilan, prinsip syura dalam menangani atau menyelesaikan permasalahan, keharaman riba, dan lain-lain. Sedangkan fiqh adalah hukum Allah yang ada unsur ijtihad manusia di dalamnya, seperti contoh masalah politik pemerintahan (fiqh siyasah), poligami, dan lain-lain. Juga bagaimana teknis menegakkan keadilan, prinsip shura diatas yang dalam hal ini sangat inheren dengan persoalan siyasah shariyah atau katakanlah semacam kebijakan baik yang menyangkut bidang ekonomi, politik, sosial, budaya, pertahanan, dan keamanan yang harus diambil pemerintah (pemimpin legalformal) demi kemaslahatan rakyat banyak. Dan dalam lapangan inilah operasionalisasi konsep maslahat dari hukum Islam akan banyak berperan, termasuk juga dalam bidang mu'amalah lainnya.

\section{Ontologi Konsep Maslahat dan Epistimologi dalam Hukum Islam}

Kata maslahat sebenarnya telah dibakukan penggunaannya dalam bahasa Indonesia (maslahat) yang berarti sesuatu yang mendatangkan kebaikan, guna, faedah. Dari makna leksikalnya ini, kiranya mengilhami kata maslahat tersebut dalam penggunaan selanjutnya. Kemudian secara terminologis, al-Syatibi (1994 : 339) mendefinisikan maslahat sebagai berikut:

Yang saya maksud dengan maslahat di sini adalah sebagai sesuatu yang dapat mendatangkan kebaikan dan keselamatan bagi kehidupan manusia yang memungkinkan akhirnya manusia bisa mendapatkan kenikmatan dan kebahagiaan baik di dunia maupun di akhirat kelak.Hal ini tidak akan tercapai dengan sendirinya secara i'tiyad (kebiasaan) semata, karena segenap maslahat itu sedikit banyaknya berkaitan dengan berbagai macam keharusan dan kesulitan, baik dalam waktu yang bersamaan, atau sebelumnya, maupun sesudahnya, seperti halnya makan, minum,pakaian, perumahan, kendaraan, pernikahan, dan lain-lain yang itu semua tidak akan diperoleh kecuali dengan kerja keras yang memayahkan. (1994:339). 
Definisi yang agak panjang diatas, kiranya kalimat utama yang merupakan pokok pikiran yang ingin disampaikan al-Shatibi terletak pada kalimat-kalimat pertama. Untuk lebih memperjelas lagi apa makna istilah dari maslahat diatas ada baiknya juga dikutip definisi yang diberikan oleh Muhammad Sa'id Ramadan aI-Buti (1997:2) bahwa maslahat adalah menjaga dan memelihara agama yang Allah SWT turunkan kepada hamba-Nya, menjaga kesehatan dan jiwa manusia, menjaga akal agar bisa berfikir dan berkata dengan benar, menjaga keturunan agar terpelihara nasabnya, serta menjaga harta agar terhindar dari perbuatan riba dan lain-lain.

AI-Buti nampaknya lebih memperjelas definisi sebelumnya, yang intinya bahwa setiap syari'at yang diberlakukan oleh Penciptanya terhadap hamba-hambaNya pasti di balik itu mempunyai tujuan itu tidak ada la in kecuali demitercapainya kemaslahatan itu sendiri.

Berikutnya, ada empat kategorisasi dalam hubungannya dengan pembagian maslahat seperti yang dilakukan oleh Husayn Hamid Hassan.Salah satunya yang menurut hemat penulis diprioritasikan untuk ditampilkan dalam makalah ini adalah maslahat dipandang dari segi keberadaan legitimasi Shari` (melalui nash-nash sarih, baik dari aI-Qur'an maupun dari Hadis) terhadapnya terbagi menjadi tiga, yaitu maslahat mu'taborah, maslahat mulghah/batilah, dan maslahat mursaloh.

Yang disebut pertama[maslahatmu'tabarah) lebih dimaknai maslahat yang mendapat legitimasi Shari', khususnya yang menyangkut limahal mendasar(at-daruriyyatal-khams) dalam agama, seperti yang berkenaan dengan keselamatan agama, jiwa, akal, keturunan,dan harta benda. Dalam kaitan aplikasi maslahat yang pertama ini dilakukan cara qiyas.

Kemudian yang disebut kedua(maslahat mulghah/batilah) lebih diartikan,suatu maslahat yang tidak diakui (dibatalkan) keberadaannya karena bertentangan dengan nash yang sharih selain maslahat tersebut cenderung menafikan ke lebih besar. Contoh kasus yang sering dikutip dalam beberapa referensi, yaitu ketika seorang gubernur Spanyol yang bernama 'Abd AI-Rahman b.AI-Hakam meminta fatwa kepada seorang ulama bernama Yahyab.Yahya al-Laythi(pengikutMalik) perihal kafarat yang harus ia('AbdaIRahman b.aI-Hakam) penuhi karena ia telah menggauli salah satu istrinya di siang hari pada bulan Ramadan, sedang ia dalam keadaan berpuasa.LalualLaythi memberikan fatwanya, bahwa ia harus bebas dua bulan berturut-turut 
Kemaslahatan dalam Fiqh Islam (Jawaban atas pandemi Covid-19)

tanpa melihat urutan kafarat seperti yang termaktub dalam nash Hadis(membebaskan budak,berpuasa selama 2 bulan berturut-turut, dan memberi makan 60 fakir miskin) karena ia berpandangan, bahwa inilah yang lebih maslahat sebagaimana terapi yang paling mujarab bagi gubernur. Dalam pada itu, seperti termaktub dalam nash hadis tentang kafarat batalnya puasa sebab menggauli istri, hal ini dipahami oleh jumhur ulama sebagai pemahaman tartib (kronologis, mendahulukan yang dahulu dan mengakhirkan yang akhir). Sedangkan Malik lebih memahami sebagai alternatif(takhyir). Melihat ini, diantara ulama ada yang bertanya: "Mengapa Anda(aI-Laythi) tidak memberikan fatwa menurut madhhab Malik, yaitu terdapat kesempatan memilih salah satu dari tiga alternatif seperti tersebut dalam Hadis?". Lalu AlLaythi menjawab: "Andaikata saya berikan fatwa seperti itu niscaya sang gubernur itu akan terus berbuat begitu setiap siang hari sambil memerdekakan budak atau memberi makan 60 orang miskin." Inti dari riwayat ini adalah sekalipun fatwa yang diberikan di atas mengacu pada maslahat, khususnya bagi gubernur(karenasetidak-tidaknya dapat membuatnya jera), akan tetapi karena bertentangan dengan maslahat sebagaimana yang diakui sendiri oleh Shari' bahwa masalah perbudakan harus secepatnya dihilangkan di atas bumi ini sehingga ia diucapkan oleh Nabi SAW tepat pada urutan pertama maka dengan sendirinya maslahat seperti yang dikehendaki oleh aI-Laythi diatas batal dengan sendirinya. (Hassan,1971:16)

Adapun yang disebut terakhir (maslahat mursalah) adalah sesuatu yang dianggap maslahah umum namun tidak ada ketegasan hukum untuk merealisasikannya dan tidak pula ada dalil tertentu baik yang mendukung maupun yang menolaknya. Jadi, sebagaimana tercermin dari kata mursalah yang berarti "terlepas/bebas" maka dalam maslahat ini memang sama sekali tidak ditemukan dalil nash secara khusus ataupun ymo' dalil yang membolehkan atau melarangnya. Berbeda dengan kedua maslahat sebelumnya yang masih terkait dengan dalil nash ataupun ymo' walaupun tidak secara langsung.

\section{Otoritas Maslahat di Hadapan Nash: Kasus aI-Tufi (673-716H.)}

Sulayman Najm Al-Din al-Tufi al-Hambali adalah salah satu ulama ahli Ushul Fiqh yang mempunyai pendapat yang agak berbeda tentang kemaslahatan ini dibandingkan dengan pendapat ulama Ushul Fiqh pada umumnya: Beliau berpendapat, bahwa apabila terjadi pertentangan antara 
teori kemaslahatan dengan nash, maka teori kemaslahatan yang dipertimbangkan terlebih dahulu.

Hasan (1971 : 530-536) menyimpulkan ada 4 (empat) prinsip kemaslahatan yang dikemukakan oleh Al-Tufi, yaitu:

a. Akal manusia mampu menilai perbuatan mana yang maslahat dan mana yang mudharat.

b. Maslahat merupakan dalil (sumber hukum) yang berdiri sendiri.

c. Maslahat diterapkan dalam bidang muamalah bukan dalam bidang ibadah.

d. Maslahat adalah salah satu sumber hukum (dalil) yang kuat.

Dari ke 4 (empat) prinsip tersebut di atas, maka teori kemaslahatan akan diutamakan dengan catatan harus menggunakan al-takhsis wa al-bayan bukan al-ta'wil wa al-iftiat. Pembagian seperti itu terkesan dipaksakan (altakalluf wa al-ta'assuf). Al-Tufi berpandangan bahwa maslahat bisa dianggap sebagai dalil syar'i, asal sesuai dengan tujuan syariat.

Kembali ke pembahasan mengenai maslahat. Apakah maslahat itu sesuatu yang tetap atau dapat berubah sesuai dengan perkembangan zaman atau perubahan sosial ? jawabannya adalah bahwa kemaslahatan itu adalah sesuatu yang bisa berubah-ubah mengikuti perubahan sosial yang ada sesuai dengan perkembangan zaman.

Persoalan berikutnya adalah bagaimana kalau kemaslahatan yang diungkapkan oleh para ahli fiqh itu tidak sesuai dengan kemaslahatan yang dimaksudkan dalam al-Qur'an dan as-Sunnah? Maka menurut pendapat yang masyhur harus mengedepankan kemaslahatan yang sesuai dengan nash dan tujuan yang utama itu (yang sering disebut dengan maqasid syariah/al-kulliyat al-khams). Jika jawabannya adalah "ya", berarti terdapat pengabaian terhadap prinsip, bahwa kemaslahatan itu dapat berubah karena perubahan sosial. Sebaliknya jika jawabannya "tidak", maka pada gilirannya agama akan kehilangan eksistensinya. Oleh karena itu, diperlukan adanya pemilahan antara nash-nash yang harus diaplikasikan sebagaimana ia diaplikasikan pada masa Nabi SAW dannash-nashyang aplikasinya memerlukan modifikasi baru sesuai dengan tuntutan perubahan sosial. Tentunya, hasil modifikasi tersebut harus tetap efektif dapat memelihara Al-khamsah diatas.

JAS: Volume 2 Nomor 1, 2020 
Kemaslahatan dalam Fiqh Islam (Jawaban atas pandemi Covid-19)

Fazlur Rahman (1982 : 5-7) dalam buku Islam and Modernity mengatakan, bahwa dalam merealisasikan kemaslahatan yang sesuai dengan maqasid syariah, maka diperlukan hal-hal sebagai berikut:

a. Harus memahami secara komprehensif historis nash-nash, baik al-Qur'an maupun as-Sunnah yang bisa membawa kemaslahatan.

b. Membuat klasifikasi antara tujuan nash yang substansif dengan kaidah fiqh yang dipergunakan dalam menetapkan kemaslahatannya.

c. Mengidentifikasi antara tuntunan nash dengan perkembangan sosial yang ada.

d. Dalam merumuskan aturan hukum terutama yang berkaitan dengan kemaslahatan harus tetap mengacu pada dalil nash yang Qath'i sesuai dengan maqasid syariahnya.

Dari pendapat di atas, maka para ahli Ushul Fiqh sangat hati-hati dalam menentukan landasan hukum tentang kemaslahatan ini, terutama dalam mensikapi pendapat al-Tufi yang lebih condong menggunakan akal nash alQur'an dan as-Sunnah.

Pembicaraan mengenai otoritas maslahat dihadapan nash ini, kiranya dapat dihasilkan suatu pandangan yang kongkrit tentang posisi dan keberadaan maslahat itu sendiri dengan mengajukan tesis dari dua orang yang sama-sama mengarahkan kajiannya pada maslahat yang pada intinya sama namun dengan argumentasi yang sedikit berbeda. Al-Buti mengajukan pendapat bahwa maslahat bisa menjadi tasyri' meskipun tidak ada perbuatan yang sesuai dengan ketentuan dalil syara' asal tidak bertentangan dengan alQur'an dan as-Sunnah. Sedangkan Husayn Hamid Hasan (1971 : 12-14) dalam disertasinya menyatakan, bahwa maslahat yang dapat dijadikan sebagai rujukan adalah maslahat yang mendapat legitimasi syara' secara umum. Dan maslahat itu adalah maslahat yang umum, bukan maslahat yang sifatnya parsial (asing). Maslahat seperti ini tidak dapat dijadikan rujukan, apalagi bila bertentangan dengan al-Qur'an dan as-Sunnah.

\section{A. Simpulan}

Pandemi Covid-19 adalah salah satu contoh kongkrit dan nyata dari perkembangan zaman dan perubahan sosial. Oleh karena itu dalam menyelesaikan persoalan-persoalan aktual seperti ini yang tidak ada dalil syara'nya, baik dari nash al-Qur'an maupun as-Sunnah, maka kita perlu 
menggunakan rujukan/dalil tentang kemaslahatan umum yang ada pada kaidah fiqh : dar'u al mafasidi muqaddamun 'ala jalbi al mashalihi (menolak kemudharatan, lebih didahulukan dari pada menarik kemaslahatan). Tindakan pencegahan, agar pandemi Covid-19 ini tidak menyebar lebih jauh dan menimbulkan penularan secara masif adalah salah satu tindakan yang sesuai dengan teori kemaslahatan ini

\section{Daftar Rujukan}

Abu Zahrah, Ushul Fiqh, Dar-al-Fikr al-Arabi, t.t.

Al-Syatibi, 1981, Muwafaqat fi Ushul al-Syariah, Bairut : Dar-al-Ma'rifah.

Fazlur Rahman, 1982, Islam and Modernity, Chicago : The University of Chicago Press.

Hassan, Husayn Hamid, 1971, Nazariyat al-Maslahah fi al-Fiqh al-Islami, Bairut : Dar al-Nahdah al-'Arabiyah.

Hosen, Ibrahim, 1933, Fiqh Siyasah dalam Tradisi Pemikiran Islam Klasik.

Musa, Kamil, al-Madkhal ila al-Tasyri' al-Islami, Bairut : Mu'assasat al-Risalah, t.t.

Ramadhan al-Buti, 1977, Dawabit al Maslahat fi al Syariat al-Islamiyah, Bairut : Mu'assasat al-Risalah

JAS: Volume 2 Nomor 1, 2020 